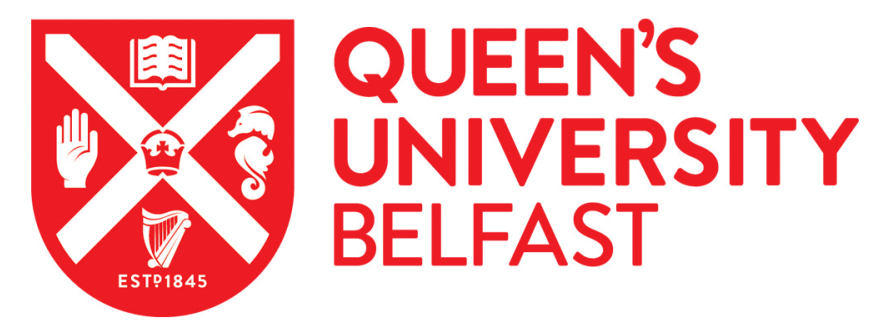

\title{
Effects of the stockperson on dairy cow behaviour and milk yield
}

Hanna, D., Sneddon, I. A., Beattie, V. E., \& Breuer, K. (2006). Effects of the stockperson on dairy cow behaviour and milk yield. Animal Science, 82(6), 791-797. https://doi.org/10.1017/ASC2006092

\section{Published in:}

Animal Science

Document Version:

Publisher's PDF, also known as Version of record

Queen's University Belfast - Research Portal:

Link to publication record in Queen's University Belfast Research Portal

Publisher rights

Copyright (C) British Society of Animal Science 2006

\section{General rights}

Copyright for the publications made accessible via the Queen's University Belfast Research Portal is retained by the author(s) and / or other copyright owners and it is a condition of accessing these publications that users recognise and abide by the legal requirements associated with these rights.

Take down policy

The Research Portal is Queen's institutional repository that provides access to Queen's research output. Every effort has been made to ensure that content in the Research Portal does not infringe any person's rights, or applicable UK laws. If you discover content in the Research Portal that you believe breaches copyright or violates any law, please contact openaccess@qub.ac.uk. 


\section{Animal Science}

http://journals.cambridge.org/ASC

Additional services for Animal Science:

Email alerts: $\underline{\text { Click here }}$

Subscriptions: $\underline{\text { Click here }}$

Commercial reprints: $\underline{\text { Click here }}$

Terms of use : $\underline{\text { Click here }}$

\section{Effects of the stockperson on dairy cow behaviour and milk yield}

D. Hanna, I. A. Sneddon, V. E. Beattie and K. Breuer

Animal Science / Volume 82 / Issue 06 / December 2006, pp 791 - 797

DOI: 10.1017/ASC2006092, Published online: 13 March 2007

Link to this article: http://journals.cambridge.org/abstract \$1357729806000956

How to cite this article:

D. Hanna, I. A. Sneddon, V. E. Beattie and K. Breuer (2006). Effects of the stockperson on dairy cow behaviour and milk yield. Animal Science, 82, pp 791-797 doi:10.1017/ASC2006092

Request Permissions : $\underline{\text { Click here }}$ 


\title{
Effects of the stockperson on dairy cow behaviour and milk yield
}

\author{
D. Hanna ${ }^{\dagger}$, I. A. Sneddon, V. E. Beattie and K. Breuer \\ School of Psychology, The Queen's University of Belfast, Belfast BT7 1NN, UK \\ ${ }^{\dagger} E-m a i l:$ donncha.hanna@qub.ac.uk
}

\begin{abstract}
The relationship between stockperson behaviour, measured as verbal and physical interactions with the dairy cows (no. = 210), during milking and the subsequent milk yield obtained was examined. The numbers of steps and kicks made by the cows during milking was recorded. The behaviour of two stockteams, each consisting of two stockmen, were recorded over 10 weekend sessions. The two teams varied in the types of interactions and when the stockteam that performed more positive interactions worked with the cows (team A), the cows had a significantly higher milk yield $(\mathrm{P}<0.05)$ although this difference was small $(17.54 \mathrm{v} .17 .44 \mathrm{~kg})$. When team $A$ was milking the cows also stepped and kicked on the platform significantly more $(\mathrm{P}<0.05)$ compared with team $B$. The results also indicated that while each stockteam tended to interact with the same cows each session, different stockpersons interacted with different cows. These findings highlight the importance of the rôle of the stockperson in milk output and dairy cow behaviour in a commercial setting.
\end{abstract}

Keywords: dairy cows, handling, human-animal interaction, productivity.

\section{Introduction}

The influence that the stockperson exerts on the productivity of dairy cows has been well documented. In 1972, Seabrook published a study on 12 herds of Friesian cows that were of similar genetic merit and under one person's ownership. Each herd had almost identical physical inputs. The only factor that differed between herds was the stockperson, yet there were significant differences in the milk yield between the herds of up to $20 \%$. Other studies have continued to report the stockperson's influence on milk production. Rushen et al. (1999) have suggested that the presence of an aversive handler during milking can increase the amount of residual milk by up to $70 \%$. Furthermore, Seabrook (1984) found that there was a significant reduction of $13 \%$ in the milk yield of cows that were treated aversively compared with those that were handled more gently. More recently, Breuer et al. (1997) discovered that a reduced milk yield can be the result of aversive physical treatment of cows directly before and after milking. The differences in milk yields due to the stockperson are often attributed to hormonal changes that are a consequence of stress (Bremel and Gangwer, 1978; Bruckmaier and Blum, 1998).

Many of the investigations that focus on stockperson-animal interactions are based on artificial handling situations in which animals are allocated to various treatment groups (e.g. Breuer et al., 1997; Rushen et al., 1999; Pajor et al., 2000). While comparisons are often drawn between aversive (or negative) treatments and gentle (or positive) treatment such studies only offer relative results. Furthermore, the treatments can vary between experiments. For example, the gentle treatment may refer to offering the cows food (Munsgaard et al., 2001), brushing the cows on their back with a soft brush only if they approach the stockperson (Boivin et al., 1998), stroking and patting during feeding (Jago et al., 1999) or brushing by a familiar stockperson during milking in an isolation chamber (Rushen et al., 2001). While aversive treatments can refer to subjecting the cows to tail twists, loud shouting, an electric cattle prod or being hit by the experimenter (Pajor et al., 2000). This research, although important, does not address stockperson handling in commercial situations which may be less marked than the extremes employed in experimental treatments. This conjecture has two important implications. First, if stockperson behaviour is not as extreme as the imposed experimental conditions it may not have a significant effect on the cows' milk yield or behaviour. Secondly, in experimental conditions each cow is exposed to exactly the same treatments whereas it is unlikely that each cow receives the same number and quality of interactions from the stockperson in a commercial situation. Cows may receive different quantities and types of interactions from the stockperson at every milking which would have important ramifications with respect to the cows' milk yield, behaviour and learning experience. This study attempted to address these points by investigating, in a commercial setting, if the stockteam would have a significant effect on milk yield and also to investigate the consistency of the stockteam's behaviours when they are interacting with the cows. 
In should be noted that there have been a limited number of studies (namely, Breuer et al., 2000; Hemsworth et al., 2000; Hemsworth et al., 2002) which have attempted to assess the stockperson's influences across commercial dairy farms. However, these farms also differed in the herd size, number of stockpersons, genetic merit of the stock, level of supplementary feeding and other factors; all of which affect the behaviour and milk production of cows rendering it difficult to isolate the effect of the stockperson.

Individual differences in the behaviour of cattle may be an essential aspect in determining the success of the humananimal working relationship. For example, it has been reported that cows classed as highly temperamental are more sensitive to touch, sounds and motion (Lanier et al., 2000). One observable trait that has been suggested as reflective of a cow's temperament is the degree of stepping and kicking it performs. Increased leg movement is considered a sign of agitation (Grandin, 1993). The frequency of stepping and kicking during milking has been recorded by Hemsworth et al. (1987) who reported that over $80 \%$ of all flinches, steps and kicks (FSK) occur when a cow is in close contact with humans. It has therefore been suggested that FSK response is indicative of fear of humans. These behavioural indices have also been studied in relation to milk yield. Willis (1983) has investigated the relationship between the flinch, step and kick responses in relation to milk yield. Willis originally predicted before commencing his study that cows which frequently stepped and kicked detract from the dairy's efficiency. However, Willis (1983) actually discovered that increases in the performance of flinches, steps and kicks were related to a significant increase in milk yield. This study will report on cows' stepping and kicking behaviour when in the presence of stockpersons during milking.

This study attempted to determine the effect of stockperson's vocal and physical interactions on milk yield and stepping and kicking behaviour within a large dairy herd. It also sought to investigate the consistency of the stockteam's behaviour when interacting with the cows. Two teams of stockpersons milked the herd twice a day, morning and evening. The benefit of the present study over the existing literature was that the same cows and production variables were used to assess the influence of the stockperson (via milk yields), which limited many confounding variables. It also examined the difference between genuine stockperson-animal interactions as opposed to artificial handling treatments, which may be more extreme than in commercial practice.

\section{Material and methods}

Two stockteams were observed (designated as team $A$ and B). Each team consisted of two stockmen, one who was principally in charge of herding the cattle to and from the parlour and the other who milked, which entailed washing udders and attaching clusters (which were subsequently automatically removed). The four stockmen were the only regular people who worked with the cows and had been following the same weekly routines for at least the past 6 months. The stockpersons therefore were considered equally familiar with the animals and at a similar level of training. Each stockteam used the same milking techniques, took the herds into the parlour in the same order and milked using the same equipment. The milking parlour used was the 'Gascoigne' 20-point external rotary parlour with checker plate floor and automatic cluster removal.

Weekend observations were used to ensure workers or visitors did not interrupt the milkings and the cattle were not taking part in experimental procedures that may have influenced milk yields (King, 1976 and 1978). This was convenient as each team consistently worked alternative weekends throughout the year. Team A was observed for five single weekend milking sessions (Friday evening to Sunday evening) and team B was observed for another five single weekend sessions (Friday evening to Sunday evening).

\section{Animals}

The study was carried out at the Agriculture Research Institute of Northern Ireland (ARINI). The dairy herd consisted of 249 dairy cows. A proportion of the cows were housed in either an indoor intensive production system and the rest were kept in an outside grazing system. The average lactation yield of the herd was $7100 \mathrm{~kg}$. The cows calved from October to March with $50 \%$ of the herd autumn calving and the remaining $50 \%$ were spring calving. Heifers made up $43 \%$ of the herd.

Any cows that were subjected to management changes (for example, turn-out), experienced problems with disease or were involved in other research were not included in this study. This reduced the sample to 210 cows. The 210 cows included 158 Holstein Friesian and 52 Norwegian dairy cattle.

\section{Stockperson's behaviour}

Two observers recorded both behaviour and vocalisations by direct observation. The same observers were used for every session. Both observers had been present at previous milking sessions to ensure the stockpersons were accustomed to their presence. When recording the behaviour the observer remained behind the stockperson at all times (approx. 2 to $5 \mathrm{~m}$ and approximately the same distance away from the cows) and did not interact with the cows in any way. One observer followed the first stockperson as they herded the cows to the milking parlour; the other observer remained in the milking parlour observing the second stockperson. The stockperson's behaviours were recorded from when they first interacted with the cows (in pasture or shed), through herding them to the parlour and during the milking process. The observation ceased once the cow left the milking platform (usually no further interactions took place). The behaviours were recorded in situ using pen and paper. It was necessary to conduct the observations without the stockperson being aware their behaviour was being recorded. Stockpersons were informed the behaviour of the cows was being investigated. Ethics approval was obtained for this experiment and the stockmen were debriefed at the end of the study. A sample of behaviour from a separate stockperson was 
video recorded and analysed to ensure consistent inter-rater reliability between the two observers, this was shown to exceed $90 \%$ for all categories of behaviour.

When recording the interactions of the stockpersons with the cows an existing outline was adopted. Hemsworth et al. (1989) recorded the behaviour of stockpersons on pig farms and created a framework to label physical interactions. These included positive interactions (P1), mildly aversive interactions (P3) and forceful aversive interactions (P4). These categories have also been used in other published research (e.g. Coleman et al., 1998).

\section{Measuring physical interactions}

Behaviours were recorded as belonging to one of three categories based on the variables P1, P3 and P4 (Hemsworth et al., 1989; Coleman et al., 1998). This also allowed the total number of negative interactions and the percentage of negative interactions to be calculated (Coleman et al., 2000):

positive $(\mathrm{P} 1)$ - indicating patting, scratching or hand resting; mildly aversive (P3) - indicating light slaps, hits, kicks or pushes; forceful aversive (P4) - indicating forceful punches, kicks or pushes.

\section{Measuring vocal interactions}

Based on preliminary trials at the farm and the existing literature on physical interactions, vocal interactions were classified into three categories, namely:

positive (V1) - talking in low voice, encouraging sounds; mildly aversive (V3) - raised voice to shouting; forceful aversive (V4) - very loud shouts and yells.

The content of the vocalisation did not affect the categorization, as it is assumed that the tone, not content, conveyed the interaction. Again, the behaviours were recorded directly.

\section{Measuring kicks and steps}

The behaviour of the cows on the milking platform was recorded in real time via a camera and video recorder and analysed at a later date. A step was recorded every time the cow lifted one of its rear hooves off the ground. A kick was defined as raising the hoof above the level of the hock. Flinches were not recorded as this behaviour was deemed too subjective to result in a consistent measure. The steps and kicks were only measured when the stockperson was in direct physical contact with the cow, for example, when cleaning the udder and attaching clusters. (This is when over $90 \%$ of these behaviours occurred.) This was an indication of the cow's behaviour in response to the presence of the stockperson at the start of milking.

\section{Milk yield}

Milk yield was automatically recorded by flow meters linked to a computer recording system for each cow on each session.

\section{Statistical analyses}

Analysis of covariance (using team A's mean milk yield as the covariate to control for between-cow variation in base milk yield) was employed to assess the difference in milk yields between the two stockteams during the observation period. (Prior to this ANCOVA, regression analyses were carried out on individual milk yield data to control for the time difference between measurements and the individual differences due to lactation curves and each cows' calving date.)

Independent t-tests were used to examine breed differences and paired t-tests were used to evaluate difference between the number of steps and kicks performed by the cows on the milking platform (this data adhered to a Normal distribution).

Each physical and vocal interaction with a cow was correlated with the percentage deviation in milk yield for that cow, for each session. Kendall's tau-b was chosen as the appropriate correlational statistic due to the number of ties (equal values) present in the interaction measurements.

It was possible to examine the degree to which each stockteam was consistent with their interactions. The Friedman test reports the differences in interactions across sessions and the intraclass correlation indicates the consistency of the distribution of interactions across sessions (Shrout and Fleiss, 1979). These statistics were used to check if the stockteams' interactions were consistent across sessions and consistently distributed across the cows.

\section{Results}

Physical interactions with cows

Over the five sessions that were observed for each stockteam the actual number of total physical interactions performed by each team only differed by $14 \%$; stockteam $A$ completed a total of 497 and stockteam B had a total of 420 interactions (Figure 1). However, the types of physical interactions performed did differ between the teams. The majority $(74 \%)$ of team A's physical interactions were of type $\mathrm{P} 1$, that is, positive in nature. In comparison, most of team B's interactions were negative in nature (55\%). The amounts of physical forceful aversive behaviours (P4) performed were low compared with the other types of interactions for both teams. P4 interactions accounted for less than $2 \%$ of team A's total interactions and less than $4 \%$ of team B's total interactions.

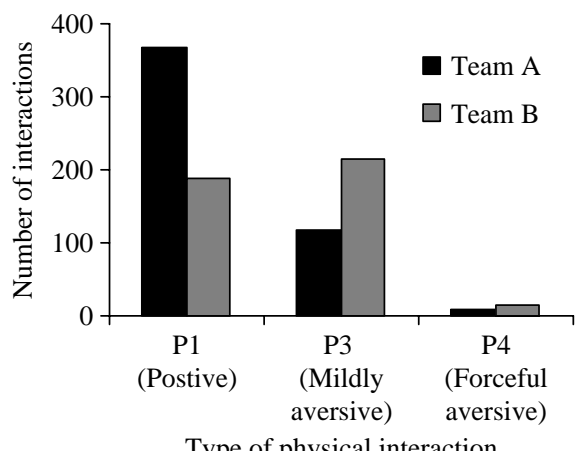

Figure 1 Total physical interactions performed by the two stockteams across five sessions. 
Vocal interactions with the cows

Figure 2 illustrates the difference in the two teams vocal interactions. Stockteam B performed 1072 interactions during the five sessions compared with the 642 vocal interactions carried out by stockteam A. The pattern of vocalisations also differed between the teams. The majority (82\%) of stockteam A's interactions were of V1 or positive vocalisations. Stockteam B, however, more commonly performed V3 behaviours $(71 \%)$ and only $27 \%$ of their total vocal interactions were positive in nature.

\section{Stockteam's effect on milk production}

Repeated measures analysis of covariance indicated that the stockteam had a significant effect on milk yield $[F(1,209)=3.93 ; p<0.05)$. Team $A$ had a higher mean milk yield of 17.54 litres per cow per day compared with team B's value of 17.44 . Analysis of milk yields over 28 weekends from September to March (when stockteams A and B milked on alternative weekends) demonstrated that stockteam $A$ had a mean yield of 23.20 per cow per day and stockteam $B$ had a mean yield of 22.47 per cow per day. However, none of the stockperson's interactions were found to significantly correlate with the deviations in milk yield.

Effect of stockteam on number of steps and kicks performed by the cows

The cows performed significantly more steps per session $(t=4.39$, d.f. $=209, P<0.001)$ when stockteam A milked (mean $=3.27$, s.d. $=1.85$ ) compared with stockteam B (mean $=2.72$, s.d. $=1.60)$. The cows also performed significantly more kicks per session $(t=5.52$, d.f. $=209, P<0.001)$ when stockteam A milked (mean $=1.28$, s.d. $=0.87$ ) compared with stockteam B (mean $=0.63$, s.d. $=1.81)$.

Significant interclass correlations demonstrated that the cows were consistent in their stepping (ICC $=0.76$; $\mathrm{F}(209,1881)=4.100, \quad P<0.001)$ and kicking behaviours $(\mathrm{ICC}=0.32 ; \mathrm{F}(209,1881)=1.41, P<0.001)$ across all the milking sessions.

\section{Differences between breeds}

Neither stockteam showed significant differences (either physical or vocal) in the frequency of their behaviours

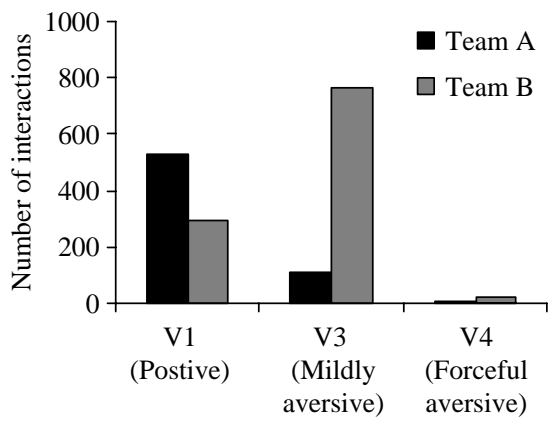

Type of vocal interaction

Figure 2 Total vocal interactions performed by the two stockteams across five sessions. when interacting with the Holstein compared with the Norwegian cows.

The number of kicks performed did not differ between the Holsteins (mean $=0.99$, s.d. $=1.24$ ) and the Norwegians (mean $=0.84$, s.d. $=0.70$ ). However, the number of steps performed did differ significantly between breed, $t=1.98$, d.f. $=208, P<0.05$. Holsteins, on average, performed 3.11 steps (s.d. $=1.52$ ) during each sessions compared with 2.64 steps $($ s.d. $=1.23$ ) for the Norwegians.

Milk yield also significantly differed between the breeds, $t=3.50$; d.f. $=208 ; P=0.001$. Holsteins had a higher mean yield of 18.06 litres per day compared with 15.70 litres for the Norwegians.

\section{Consistency in the stockteam's interactions}

During the first five sessions, when stockteam A was milking, there was no significant difference in the distribution of the positive physical interactions (P1) across the sessions $\left(\chi^{2}=3.06\right.$; d.f. $\left.=4 ; P=0.549\right)$ and there was a significant interclass correlation across these sessions (ICC $=0.70$; $\mathrm{F}=(209,836) 3.37 ; P<0.001)$. This indicates that stockteam A were relatively consistent with the distribution of their positive physical interactions across sessions and suggests the same cows tended to receive positive interactions from stockteam A across all five sessions. Similarly there was no significant difference in the distribution of the negative physical interactions (P3 $+\mathrm{P} 4)$ across the sessions $\left(\chi^{2}=1.29\right.$; d.f. $\left.=4 ; P=0.863\right)$ and there was a significant interclass correlation across these sessions $(\mathrm{ICC}=0.57 ; \mathrm{F}=(209,836) 2.34 ; P<0.001)$.

When stockteam B was milking there was no significant difference in the distribution of positive physical interactions $\left(\chi^{2}=1.29\right.$; d.f. $\left.=4 ; P=0.863\right)$ or negative interactions $\left(\chi^{2}=3.14\right.$; d.f. $\left.=4 ; P=0.534\right)$ across sessions. There were, however, significant interclass correlations for positive $(\mathrm{ICC}=0.66 ; \mathrm{F}(209,836)=2.95 ; P<0.001)$ and negative interactions $(I C C=0.64 ; F(209,836)=2.75$; $P<0.001)$ across the milking sessions. Therefore, as with stockteam A, stockteam B were consistent in the distribution of their interactions across sessions and the same cows tended to be interacted with in the same way each session.

It is now possible to examine the distribution of interactions between stockteam A and B using the interclass correlation. The middle milking session, Saturday evening, was chosen for this analysis. There was no significant correlation in the distribution of positive physical interactions $(I C C=0.05$; $\mathrm{F}(209,209)=1.05 ; P=0.357)$ or negative physical interactions $\quad(I C C=0.02 \quad F(209,209)=1.025 ; \quad P=0.429)$ between the two stockteams. These results indicate that the same cows are not receiving consistent behaviour between the stockteams. Despite the earlier assertion that stockteam $A$ and $B$ were consistent in the distribution of their positive and negative interactions (that is, within each team the same cows tended to receive same interaction across sessions), the two different teams tended to interact with different cows. 
The stockperson, dairy cow behaviour and milk yield

\section{Discussion}

Many of the existing studies on human-dairy cow interactions have focused on the effects of experimental handling treatments (Breuer et al., 1997; Rushen et al., 1999; Pajor et al., 2000; Lensink et al., 2001). These studies have demonstrated that different types of handling are important with regard to behavioural and production indices. However, this research does not successfully specify if stockpersons do employ a range of behaviours or if these behaviours vary from person to person. If the behaviour of stockpersons in normal conditions did not vary substantially there would be little practical benefit examining these behaviours (in artificial or commercial situations) or researching the underlying psychological correlates that may elicit these behaviours.

\section{Differences between teams}

There were apparent differences between stockteams in the amount and the type of interactions they performed despite the fact that all of the physical inputs were identical.

Despite the small sample size, this study suggests that the interactions of stockpersons can differ in their everyday interactions with dairy cows. There was no suggestion before this study that the stockpersons differed in their behaviour; therefore such marked variations between the teams were unexpected. The stockpersons' behaviour was certainly not unacceptable and the selection procedures and controls employed at the ARINI conform to best practice. In dairy farms where the behaviour of the stockpersons may not be subject to rigorous controls it is conceivable that greater differences in the behaviour of stockpersons may exist.

These results have applied consequences in dairy farming as previous experimental research has shown that the stockperson's behaviour can influence the cows' milk yield, avoidance behaviour and physical health (Breuer et al., 1997; Rushen et al., 1999; Pajor et al., 2000; Lensink et al., 2001). Furthermore, it highlights the importance of training and selecting dairy stockpersons to maximize production and welfare.

\section{The stockteam's influence on milk yield}

Analyses of the milk yields (during the observation and prior to this investigation) indicated that stockteam $A$ obtained a higher milk yield than stockteam $B$. The difference was relatively small $(<1 \%)$, although consistent. The differences reported in the present study are substantially less than those found in previous research which ranged from 6\% (Breuer et al., 1997) to $30 \%$ (Seabrook, 1972). The difference between the present and the previous studies may be simply because the interactions performed by the stockteams in the present study were less extreme, resulting in a smaller difference in milk yield. There may have been less difference between the groups due to the standardised selection criteria and procedures followed at the ARINI.

This study supports previous research that indicated negative handling is linked to lower milk yields (Breuer et al., 1997; Rushen et al., 1999; Pajor et al., 2000). Despite this fact there were no substantial correlations between the stockteam's interactions and milk yield. There are only two previous studies which attempt to correlate the stockperson behaviour and the subsequent milk yield which they obtain (Breuer et al., 2000; Hemsworth et al., 2000). However the results of these studies lack consistency. The lack of correlations between the interactions and milk yield may indicate that the methods used to measure the stockperson's interactions or behaviours are not effective in picking up the cues which are directly influencing the subsequent milk yields obtained. It is accepted that negative handling is detrimental to obtaining the optimum milk yield; however, there may be subtle behaviours, such as the speed of approach, arm-waving or tone of voice, which influence milk yield but are not recorded. It is therefore suggested that future studies should focus on identifying the behaviours that should be recorded.

The finding that negative handling is related to lower milk yields (Seabrook, 1972 and 1984; Breuer et al., 1997; Rushen et al., 1999) is of relevance to all dairy farmers as improved handling can lead to increases in milk yields. This is a way of increasing productivity at no financial costs to the farmer.

The stockteam's influence on the cows' behaviour The stockteam also had an influence on the behaviour of the cows while on the milking parlour. The cows stepped and kicked more when stockteam A was milking compared with stockteam B. However, there were also significant interclass correlations between these behaviours across each session indicating that these behaviours were relatively consistent. That is, the cows tended to replicate the same pattern of stepping and kicking behaviour on each session. The breed also influenced the stepping behaviour of the cows (by approximately $15 \%$ ) with Holstein cows performed significantly more stepping behaviours than the Norwegian cows. It should be noted that these results are not antithetical; a proportion of the variance observed in the stepping and kicking behaviour appears to be explained by the influence of the stockperson and another proportion appears to be explained by individual differences between the cows.

There is evidence to suggest that cows display increased movement when subjected to different types of stressors (Munskgaard et al., 2001) and this increased movement is generally viewed as a sign of agitation (Grandin, 1993). Additionally, cows which step and kick frequently are often viewed as detracting from the dairy's overall efficiency and present a potential risk to the stockperson (Willis, 1983; Rushen et al., 1999). It appears, therefore, rather contradictory that when stockteam A (which performed more positive interactions and obtained a higher milk yield) milked, the cows stepped and kicked more frequently. However these results concur with previous research that has demonstrated that cows show increased leg movement in the presence of a gentle handler as opposed to an aversive handler (Rushen et al., 1999; Munskgaard et al., 2001) and that increased leg movement may be related to increased milk yield (Willis, 1983).

It therefore appears that stepping and kicking behaviour is not a straightforward indicator of fear. The consistency in 
the behaviour across sessions and the breed differences may suggest a genetic basis is partly accountable. It has also been suggested that these behaviours may be situationally dependent (Munskgaard et al., 2001) or related to aggressiveness (Rushen et al., 1999). There may also be reciprocal relationships where the stockperson will interact more with those cows which perform the most steps and kicks (Hemsworth et al., 1989). The basis of these behaviours appears more complicated than previously thought and requires further research.

\section{Consistency of the teams}

One of the more novel discoveries that was not expected relates to the distributions of the interactions performed by the stockpersons. These results indicate that each stockteam is relatively 'internally consistent' with the distribution of its interactions. That is, the stockteams tended to interact with the same cows in the same way across sessions. However, when the behaviours of stockteam A were correlated with the behaviours of stockteam B it appeared that the teams interacted with different cows. This indicated that stockteam A did not interact with the same cows as stockteam B. Therefore different stockpersons tended to interact with different cows, but each stockperson tended to interact with the same cows each time they milked.

This finding may have several important implications. In commercial situations the stockperson will interact more with certain cows and less with others, unlike experimental conditions. This may compromise the generalizations that can be extrapolated from experimental studies. Experimental work is obviously important, but more research must be carried out in commercial dairy farms. Different stockpersons will interact with different cows which may have consequences for welfare and productivity. Future research may determine which cows are more likely to receive most negative interactions (for example, the slowest, the last one to enter the parlour, etc.) and this would be important in creating very specific training programmes for stockpersons. Additionally, individual differences between cows may predispose them to be more or less susceptible to the stockperson's interactions and the subsequent stress responses associated with these interactions. It is therefore important to consider what cows were interacted with, as well as, what interactions are used. The rôle of social learning may become a more critical factor if cows (which are interacted with less) can learn how to react appropriately by observing the stockpersons interactions on other cows (that may experience a greater proportion of the stockperson's interactions). These findings therefore call for more applied research to identify which cows receive most interactions, individual differences between cows and the rôle of social leaning in the stockperson-cow relationship.

\section{Conclusion}

This investigation found that the behaviour of the stockpersons at the ARINI did differ with respect to their physical and vocal interactions with dairy cows. The milk yield and behaviours of the dairy cows varied significantly with the stockpersons who were milking. Although the data did not allow causal inferences to be concluded the fact that the only variable that differed between the sessions was the stockteam implied that it was the stockpersons influencing the cows' behaviour and milk yield. The cows had a higher milk yield when the stockteam which performed the greatest number of positive interactions and the least number of negative interactions was milking. Similarly, the cows performed significantly more stepping and kicking behaviour when the stockteam which performed the greatest number of positive interactions and the least number of negative interactions was milking. It was also discovered that while individuals may be relatively consistent with the cows they interact with, different stockpersons will interact with different cows.

The findings of this study highlight the importance of the stockperson within dairy farming, as small differences in the stockperson's behaviour can have significant effects on both cow behaviour and milk production.

\section{Acknowledgements}

We would like to thank the stock men and staff of the Agricultural Research Institute of Northern Ireland at Hillsborough, County Down for their assistance and co-operation.

\section{References}

Boivin, X., Garel, J. P., Durier, C. and LeNeindre, P. 1998. Is gentling by people rewarding for beef calves? Applied Animal Behaviour Science 61: 1-12.

Bremel, R. D. and Gangwer, M. I. 1978. Effect of andrenocorticotropin injection and stress on milk cortisol content. Journal of Dairy Science 61: 1103-1108.

Breuer, K., Hemsworth, P. H. and Coleman, G. 1997. The effect of handling on the behavioural response to humans and productivity of lactating heifers. In Proceedings of the 31st International Congress of the International Society for Applied Ethology, p. 39

Breuer, K., Hemsworth, P. H., Barnett, J. L., Matthews, L. R. and Coleman, G. J. 2000. Behavioural response to humans and the productivity of commercial dairy cows. Applied Animal Behavioural Science 66: 273-288.

Bruckmaier, R. M. and Blum, J. W. 1998. Oxytocin release and milk removal in ruminants. Journal of Dairy Science 81: 939-949.

Coleman, G. J., Hemsworth, P. H., Hay, M. and Cox, M. 1998. Predicting stockperson behaviour towards pigs from attitudinal and job-related variables and empathy. Applied Animal Behaviour Science 58: 63-75.

Coleman, G. J., Hemsworth, P. H., Hay, M. and Cox, M. 2000. Modifying stockperson attitudes and behaviour towards pigs at a large commercial farm. Applied Animal Behaviour Science 66: 11-20.

Grandin, T. 1993. Livestock handling and transport. CAB International, Wallingford, Oxon.

Hemsworth, P. H., Barnett, J. L., Coleman, G. J. and Hansen, C. 1989. A study of the relationships between the attitudinal and behavioural profiles of stockpersons and the level of fear of humans and reproductive performance of commercial pigs. Applied Animal Behaviour Science 23: 301-314

Hemsworth, P. H., Coleman, G. J., Barnett, J. L. and Borg, S. 2000. Relationships between human-animal interactions and productivity of commercial dairy cows. Applied Animal Behavioural Science 78: 2821-2831.

Hemsworth, P. H., Coleman, G. J., Barnett, J. L., Borg, S. and Dowling, S. 2002. The effects of cognitive behavioural intervention on the attitude and behaviour of stockperson and the behaviour and productivity of commercial dairy cows. Applied Animal Behavioural Science 80: 68-78. 


\section{The stockperson, dairy cow behaviour and milk yield}

Hemsworth, P. H., Hansen, C. and Barnett, J. L. 1987. The effects of human presence at the time of calving of primiparous cows on their subsequent behavioural response to milking. Applied Animal Behaviour Science 18: 247-255.

Jago, J. G., Krohn, C. C. and Matthews, L. R. 1999. The influence of feeding and handling on the development of human-animal interactions in young cattle. Applied Animal Behaviour Science 62: 137-151.

King, J. O. L. 1976. The effect of disturbances on milk production in cows. The Veterinary Record 98: 41-42.

King, J. O. L. 1978. The effects of visiting parties on milk production in cows. The Veterinary Record 102: 361-362.

Lanier, J. L., Grandin, T., Green, R. D., Avery, D. and McGee, K. 2000. The relationship between sudden intermittent movements and sounds and temperament. Journal of Animal Science 78: 1467-1474.

Lensink, B. J., Raussi, S., Boivin, X., Pyykkonen, M. and Veissier, I. 2001. Reactions of calves to handling depend on housing condition and previous experience with humans. Applied Animal Behaviour Science 70: 187-199.

Munksgaard, L., de Passille, A. M., Rushen, J., Herskin, M. S. and Kristensen, X. 2001. Dairy cows' fear of people: social learning, milk yield and behaviour at milking. Applied Animal Behaviour Science 73: 15-26.
Pajor, E. A., Rushen, J. and de Passille, A. M. B. 2000. Aversion learning techniques to evaluate dairy cattle practices. Applied Animal Behaviour Science 69: 89-102.

Rushen, J., de Passille, A. M. and Munksgaard, L. 1999. Fear of people by cows and effects on milk yield, behaviour and heart rate at milking. Journal of Dairy Science 82: 720-727.

Rushen, J., Munksgaard, L., Marnet, P. G. and de Passille, A. M. 2001. Human contact and the effects of acute stress on cows at milking. Applied Animal Behaviour Science 73: 1-14.

Seabrook, M. F. 1972. A study to determine the influence of the herdsman's personality on milk yield. Journal of Agriculture Labor Science 1: 45-49.

Seabrook, M. F. 1984. The psychological interaction between the stockman and his animals and its influence on performance of pigs and dairy cows. Veterinary Record 115: 84-87.

Shrout, P. E. and Fleiss, J. L. 1979. Intraclass correlations. Psychological Bulletin 86: 420-427.

Willis, G. L. 1983. A possible relationship between the flinch, step and kick response and milk yield in lactating cows. Applied Animal Ethology 10: 287-290.

(Received 26 January 2006-Accepted 4 July 2006) 